\title{
Physical and rheological properties of nano zinc oxide modified asphalt binder
}

\author{
Khairul Nizam Mohd Yunus ${ }^{1}$, Mohd Ezree Abdullah ${ }^{1}$, Mohd Khairul Ahmad ${ }^{2}$, Nurul \\ Hidayah Mohd Kamaruddin ${ }^{1, *}$, and Haniffah Tami ${ }^{1}$ \\ ${ }^{1}$ Faculty of Civil and Environmental Engineering, UTHM, 86400 Batu Pahat, Johor, Malaysia \\ ${ }^{2}$ Microelectronic and Nanotechnology-Shamsuddin Research Centre (MiNT-SRC), UTHM, 86400 \\ Batu Pahat, Johor, Malaysia
}

\begin{abstract}
The main objectives of this work were to investigate the physical and rheological properties of nano zinc oxide $(\mathrm{NaZO})$ flake structure as a modifier in asphalt binder. $\mathrm{NaZO}$ was produced with hydrothermal method by using two precursors, which are zinc nitrate and sodium hydroxide. NaZO was mixed with virgin binder $60 / 70$ penetration grade at $3 \%, 5 \%$ and $7 \%$ of asphalt binder weight, respectively. The physical properties were evaluated by conventional testing, such as penetration, softening point and viscosity. Meanwhile, the rheological property, such as rutting resistance, was measured by using a dynamic shear rheometer (DSR) for unaged and rolling thin film oven (RTFO) aged. It was observed that the penetration value was decreased and the softening point increased with increasing $\mathrm{NaZO}$ concentrations. In addition, the rutting resistance factor was increased for the modified binder. A comparison between the modified binder, $7 \% \mathrm{NaZO}$, showed a greater resistance to rutting before and after aging. Results of this study showed that the NaZO addition had increased the asphalt binder stiffness ; thus, could contribute to better resistance to permanent deformation.
\end{abstract}

\section{Introduction}

In recent years, nanotechnology has become a promising and creative technique in material industry and nanomaterials were widely appliedin various fields across the world. There are various nanomaterials which were or have the potential to modifyasphalt, such as nanoclay, nanosilica, nanohydrated lime, nanosized plastic powders (or polymerized powders) nanofibers, nanotubes and nanocharcoal [1]-[3]. Another nanomaterial commonly used for asphalt modification is nano zinc oxide ( $\mathrm{NaZO}$ ). $\mathrm{NaZO}$ is commonly available as white powder. It is used in many industries, such as paints, cosmetics, plastic and rubber manufacturing and electronics, because of its unique and special properties [4]. Recently, this nanomaterial has attracted the attention of asphalt pavement researchwith more positive results expectation. Previous research have shown that NaZO particles can improve antirutting factors [5]. It was also observed that $\mathrm{NaZO}$ can contribute to a homogenous dispersion and decrease the average size of bee-like structure particles in asphalt binder [6].

\footnotetext{
*Corresponding author: hidayahk@uthm.edu.my
} 
Hamedi et al. (2015) found that NaZO particle was able to decrease asphalt binder acidity, which led to a positive effect on asphalt binder and acidic aggregate adhesion, such as granite; consequently, the indirect tensile strength for unconditioned and conditioned asphalt mixture samples were significantly improved [7]. The most common nanostructure used in these modification was spherical in shape. However, little work was carried out by using NaZO in flake structure on properties of asphalt binder. The effects of other NaZO shapes are still unclear. Therefore, this study was initiated to investigate the NaZO flake structure on physical and rheological properties of asphalt binder.

\section{Materials and Experimental Procedures}

\subsection{Materials}

In this study, a virgin asphalt binder of penetration grade 60/70 was used as the control sample. Basic properties of the virgin asphalt binder are shown in Table 1. Meanwhile, NaZO was produced from a hydrothermal process by using two precursors: zinc nitrate hexahydrate $\left(\mathrm{Zn}\left(\mathrm{NO}_{3}\right)_{2} \cdot 6 \mathrm{H}_{2} \mathrm{O}\right)$ and sodium hydroxide $(\mathrm{NaOH})$. Physical properties of $\mathrm{NaZO}$ are given in Table 2 and the morphology of NaZO is shown in Figure 1. The figure shows the NaZO structure as flakes with size from 10 to 30 nanometers.

Table 1. Basic properties of virgin asphalt binder.

\begin{tabular}{|c|c|}
\hline Properties & Value \\
\hline $\begin{array}{c}\text { Penetration } \\
\left(25^{\circ} \mathrm{C}, 0.1 \mathrm{~mm}\right)\end{array}$ & 67.63 \\
\hline Softening point $\left({ }^{\circ} \mathrm{C}\right)$ & 52.30 \\
\hline $\mathrm{G}^{*} / \sin \delta$ at $64^{\circ} \mathrm{C}(\mathrm{kPa})$ & 2.151 \\
\hline $\begin{array}{c}\text { Viscosity at } 135^{\circ} \mathrm{C} \\
(\mathrm{Pa} . \mathrm{s})\end{array}$ & 0.679 \\
\hline
\end{tabular}

Table 2. Basic properties of NaZO.

\begin{tabular}{|c|c|}
\hline Properties & Description \\
\hline Solution molarity & $0.25 \mathrm{~mol} / \mathrm{L}$ \\
\hline Shape of particles & Flakes \\
\hline Production process & Hydrothermal method \\
\hline Size $(\mathrm{nm})$ & $10-30$ \\
\hline Physical appearance & Powder \\
\hline
\end{tabular}




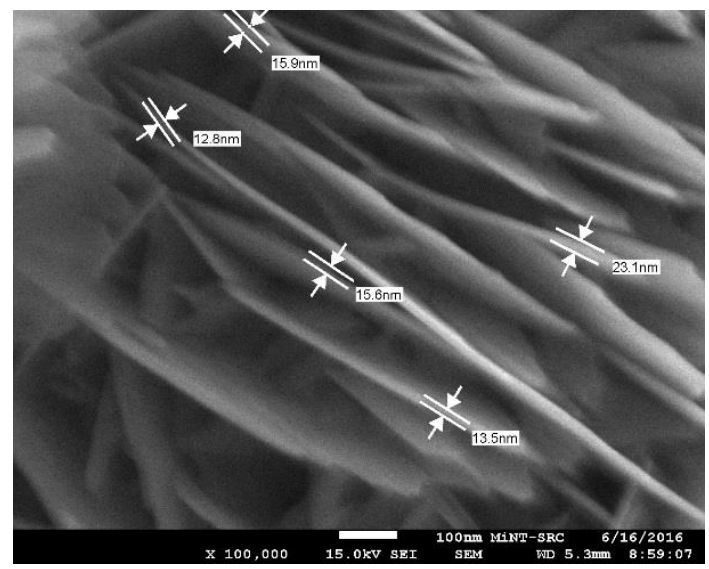

Fig. 1. Flake structure of $\mathrm{NaZO}$.

\subsection{Preparation of Nano ZnO Modified Asphalt}

NaZO modified asphalt (NAZOMA) binders were prepared by using Silverson L4RT high shear mixer with rotation speed of $2,000 \mathrm{rpm}$ and at temperature range of $135^{\circ} \mathrm{C}$ to $150^{\circ} \mathrm{C}$ for $30 \mathrm{~min}$. To acquire a homogenous dispersion, NaZO particles $(3 \%, 5 \%$ and $7 \%$ by weight of asphalt binder), were gradually added into the virgin asphalt binder. All samples were kept in storage and sealed in a container prior to testing.

\subsection{Testing Methods}

Physical properties of virgin and $\mathrm{ZnO}$ modified asphalt binder were measured by using penetration, softening point and viscosity tests. These testings were conducted in accordance with the ASTM D5 [8], ASTM D36 [9] and ASTM D4402 [10] procedures, respectively. The penetration test was to measure the asphalt material hardness, while the softening point test was corresponded to the temperature at which asphalt started to become an asphalt binder. The viscosity test was conducted at temperatures of $120^{\circ} \mathrm{C}, 135^{\circ} \mathrm{C}, 150^{\circ} \mathrm{C}$ and $165^{\circ} \mathrm{C}$. Meanwhile, the rheological properties were determined by using a dynamic shear rheometer (DSR) according to ASTM D7175 [10], with plate geometry of $25 \mathrm{~mm}$ diameter and $1 \mathrm{~mm}$ sample thickness . $\mathrm{G}^{*} / \sin \delta$ (rutting resistance) was used to define the rheological properties under different temperatures that ranged from $52^{\circ} \mathrm{C}$ to $76^{\circ} \mathrm{C}$ (at $6^{\circ} \mathrm{C}$ increments) with loading frequency of $1.592 \mathrm{~Hz}$. This test was also characterized by two conditions: unaged and rolling thin film oven (RTFO) aged. RTFO was conducted according to ASTM D2872 [11], where the asphalt binder samples were conditioned in a RTFO device at $163^{\circ} \mathrm{C}$ temperature for 85 $\min$.

\section{Results and Discussion}

\subsection{Penetration Value}

Figure 2 presents the experimental data for virgin binder and NAZOMA penetration tests. It was seen that the penetration value decreased with the presence of NaZOin the asphalt binder. The penetration value was decreased by about $7.0 \%, 3.3 \%$ and $4.4 \%$ as compared to virgin asphalt binder for $3 \%, 5 \%$ and $7 \%$ of NaZO. These results indicated the increasing binder 
hardness . However, $3 \%$ of NaZO showed a significant decrease for the penetration value as compared to $5 \%$ and $7 \%$ of $\mathrm{NaZO}$.

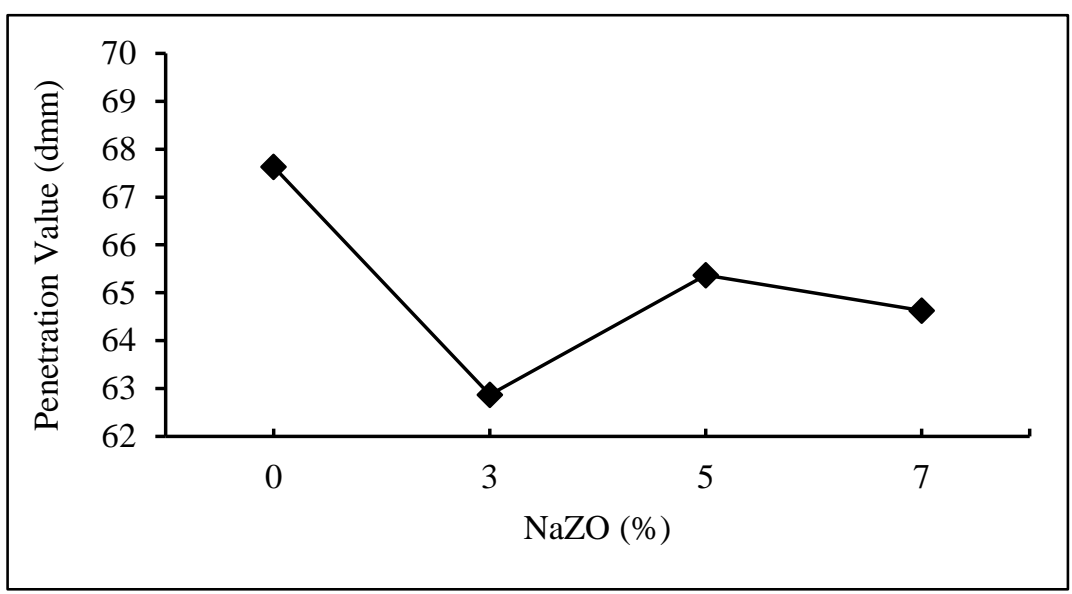

Fig. 2. Penetration value of unaged virgin and modified asphalt binder.

\subsection{Softening Point}

Figure 3 compares the softening point temperatures for virgin and NAZOMA binders. The graph shows that softening point temperature increased with the addition of NaZO. The softening point improved by $6.3 \%, 2.2 \%$ and $4 \%$ as compared to virgin asphalt binder properties for $3 \%, 5 \%$ and $7 \%$ of NaZO. It was noted that $3 \% \mathrm{NaZO}$ was higher than $5 \%$ and $7 \%$ of NaZO. The results indicated that the softening points were constantly increased as the percentage of nano $\mathrm{ZnO}$ was increased as compared to the virgin asphalt binder. The overall softening points for the various concentrations of nano $\mathrm{ZnO}$ modidfied asphalt binder were in a small range, which indicated that $\mathrm{ZnO}$ had little impact in rising the softening point. In general, the decreasing value of penetration and increasing value of NAZOMA demonstrated the increased asphalt binder hardness and stiffness, which is desirable in asphalt industry. 


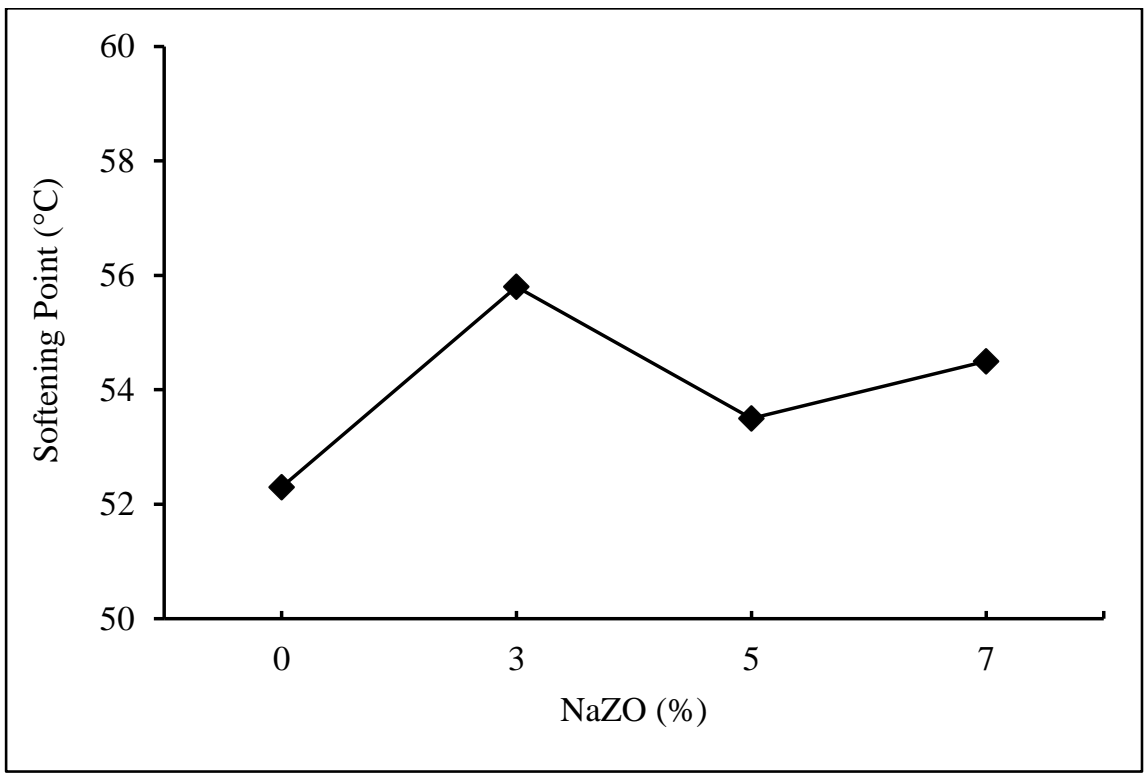

Fig. 3. Softening point for unaged virgin and modified asphalt binder.

\subsection{Viscosity}

The virgin and NaZOMA binder viscosity results are shown in Figure 4. The results indicated that the NaZO modification had increased the viscosity value of virgin binder, especially at $120^{\circ} \mathrm{C}$ and $135^{\circ} \mathrm{C}$ temperature. Meanwhile, at high temperature $\left(150^{\circ} \mathrm{C}\right.$ and $\left.165^{\circ} \mathrm{C}\right)$, the binder viscosity values were overlapped, which may indicate similarity. According to SUPERPAVE standard, the value of viscosity shall not be more than 3 Pa.s at temperature $135^{\circ} \mathrm{C}$ as to ensure the workability of the asphalt binder [12]. Based on the results all samples had satisfied this standard specification.

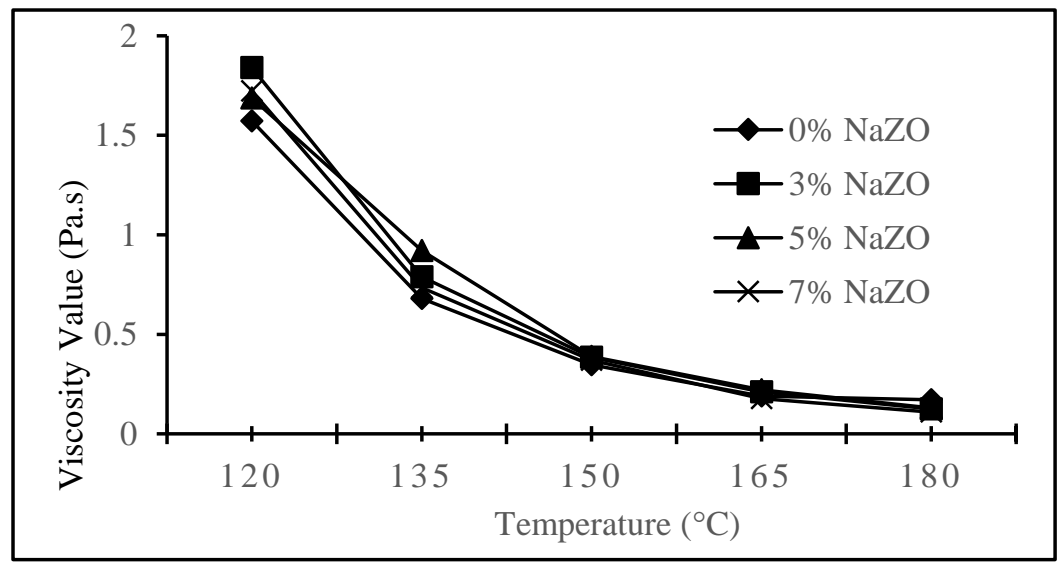

Fig. 4. Viscosity value for virgin asphalt binder and modified asphalt binder. 


\subsection{Rutting Resistance}

$\mathrm{G}^{*} / \sin \delta$ was typically used to characterize the rutting resistance of asphalt binder at high temperature. Figure 5 and Figure 6 depicted rutting parameter, $\mathrm{G}^{*} / \sin \delta$ values, for virgin and NAZOMA binder. As observed, $\mathrm{G}^{*} / \sin \delta$ for unaged value were increased for $3 \%$ and $7 \%$ of $\mathrm{NaZO}$ as compared to the virgin asphalt binder. However, the $\mathrm{G}^{*} / \sin \delta$ value for unaged were decreased for $5 \%$ of nano $\mathrm{ZnO}$ as the percentage of additive was increased. In Figure 8, 3\% and 7\% of NaZO increased the $\mathrm{G}^{*} / \sin \delta$ value for RTFO aging as compared to virgin asphalt binder. Meanwhile, $5 \%$ of $\mathrm{NaZO}$ had the same $\mathrm{G}^{*} / \sin \delta$ value as virgin asphalt binder. Both figures show that $3 \%$ and $7 \%$ of $\mathrm{NaZO}$ have more $\mathrm{G} * / \sin \delta$ for unaged and RTFO gaining. Based on the Asphalt Institute specification, $\mathrm{G}^{*} / \sin \delta$ for unaged asphalt binder should be more than $1 \mathrm{kPa}$ at the test temperature. Meanwhile for asphalt binder after RTFO aging, G*/sin $\delta$ should be more than $2.2 \mathrm{kPa}$. This demonstrated that NAZOMA binder was able to enhance the asphalt binder rutting resistance .

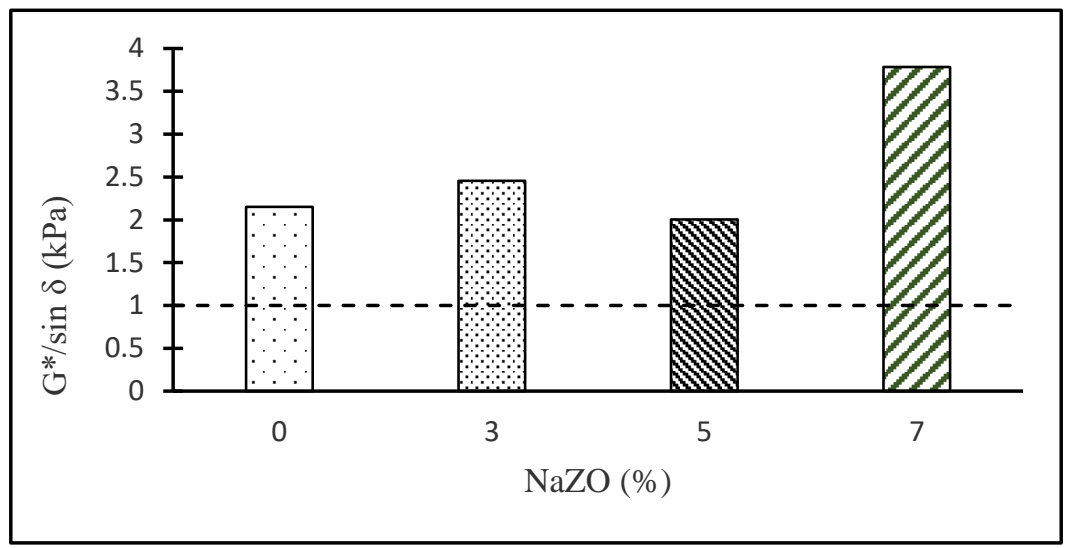

Fig. 5. Rutting resistance for unaged condition at temperature $64^{\circ} \mathrm{C}$.

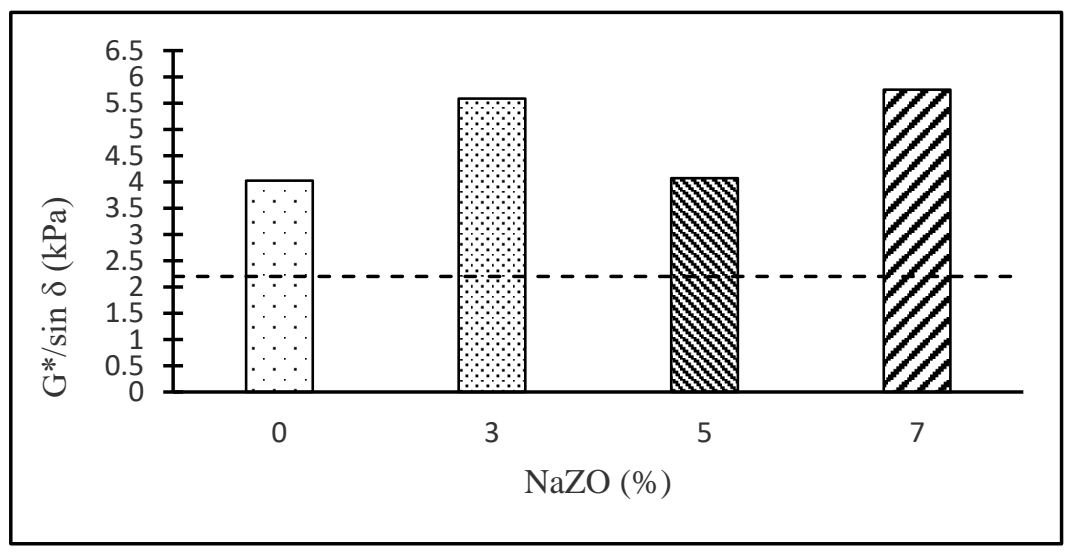

Fig. 6. Rutting resistance for short-term aged condition at temperature $64^{\circ} \mathrm{C}$. 


\subsection{Failure temperature}

The samples were tested at $52^{\circ} \mathrm{C}$ initial temperature and the temperature was increased by about $6^{\circ} \mathrm{C}$ for each increment until failure ( $1 \mathrm{kPa}$ for unaged and $2.2 \mathrm{kPa}$ for short term aged). Figure 7 and Figure 8 illustrate the failure temperature results for unaged and short term aged. The results showed that the addition of NAZOMA increased the failure temperature as compared to the virgin binder. 7\% of NAZOMA displayed the highest failure temperature, while virgin asphalt binder $(0 \%$ of NaZO) had the lowest failure temperature. The NAZOMA effect mechanism was similar to softening point.

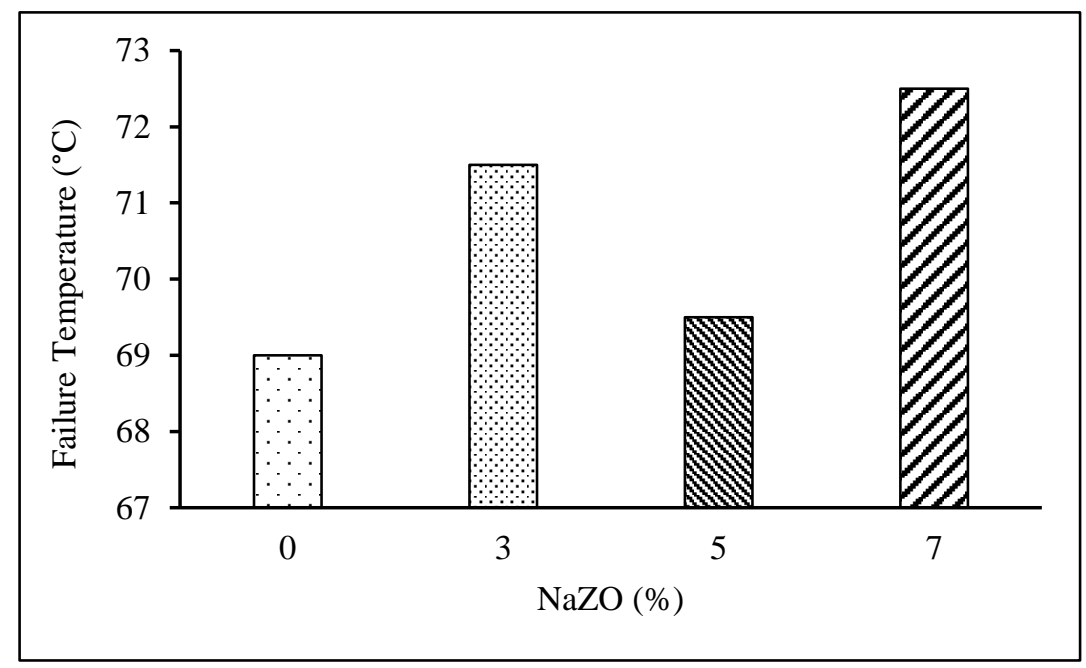

Fig. 7. High failing temperature of unaged virgin and modified asphalt binder.

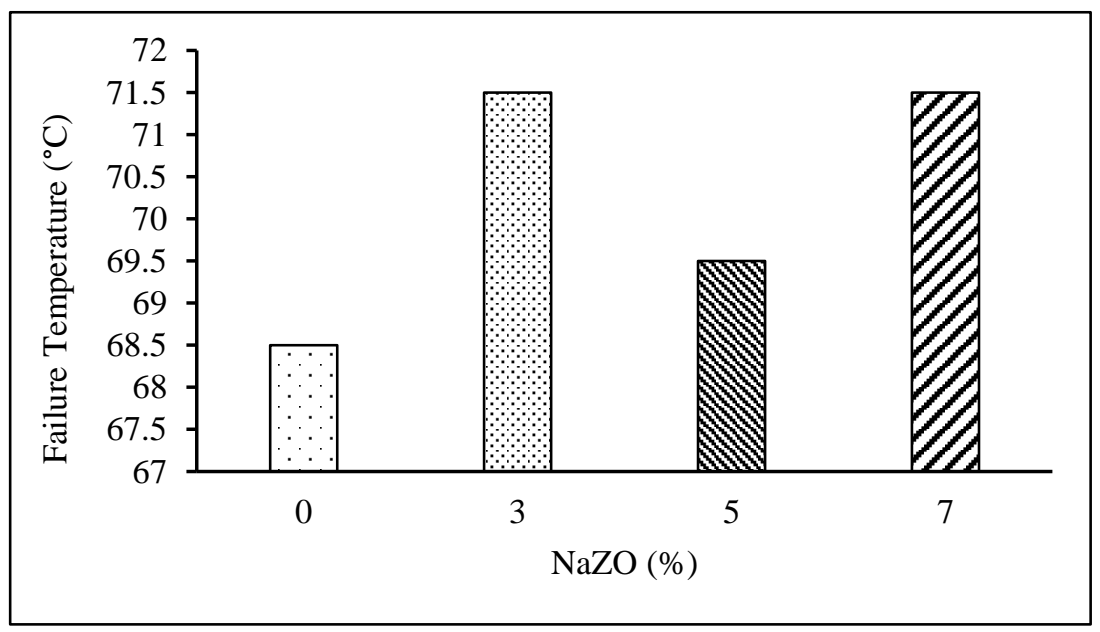

Fig. 8. High failing temperature of short-term aged. 


\section{Conclusions}

This study assessed the different percentages of NaZO flake particles in PEN 60/70 virgin asphalt binder modification. The NaZO addition has significantly improved the asphalt binder penetration and softening points . This demonstrated the improvement in asphalt binder stiffness and better temperature susceptibility. In addition, NAZOMA binder showed an increased rutting resistance, which was expected by an increase in the $\mathrm{G}^{*} / \mathrm{sin} \delta$ parameter at $64^{\circ} \mathrm{C}$ testing temperature. As a result, the NAZOMA failure temperature was higher as compared to virgin asphalt binder. In conclusion, $\mathrm{NaZO}$ with flake particles is a good substance for an additive in asphalt binder because it improves the physical and rheological characteristics . Further studies are needed to determine the advantages of NaZO with flake particles, which is expected to improve the asphalt binder and aggregate adhesion.

The authors wish to acknowledge the support from Universiti Tun Hussein Onn Malaysia (UTHM) for the grant TIER 1 H115.

\section{References}

1. N. I. M. Yusoff, A. A. S. Breem, H. N. M. Alattug, A. Hamim, and J. Ahmad, "The effects of moisture susceptibility and ageing conditions on nano-silica/polymermodified asphalt mixtures," Constr. Build. Mater., 72, pp. 139-147 (2014)

2. M. E. Abdullah, K. A. Zamhari, M. R. Hainin, E. A. Oluwasola, N. A. Hassan, and N. I. M. Yusoff, "Engineering properties of asphalt binders containing nanoclay and chemical warm-mix asphalt additives," Constr. Build. Mater., 112, pp. 232-240 (2016)

3. S. N. A. Jeffry, R. P. Jaya, N. A. Hassan, H. Yaacob, J. Mirza, and S. H. Drahman, "Effects of nanocharcoal coconut-shell ash on the physical and rheological properties of bitumen," Constr. Build. Mater., 158, pp. 1-10 (2018)

4. M. H. Mamat and M. Z. Sahdan, "Electrical characteristics of sol-gel derived aluminum doped Zinc Oxide thin films at different annealing temperatures," International Conference on Electronic Devices, Systems and Applications (ICEDSA2010) , pp. 408411, 2010.

5. H. Zhang, Y. Gao, G. Guo, B. Zhao, and J. Yu, "Effects of ZnO particle size on properties of asphalt and asphalt mixture," Constr. Build. Mater., 159, pp. 578-586 (2018)

6. P. F. Du, N. X. Ke, and H. L. Zhang, "Effect of Nano-zinc oxide on the morphology and ultraviolet aging properties of various bitumens," Pet. Sci. Technol., 33 (10), pp. 1110-1117 (2015)

7. G. H. Hamedi, F. M. Nejad, and K. Oveisi, "Estimating the moisture damage of asphalt mixture modified with nano zinc oxide," Mater. Struct., pp. 1-10 (2015)

8. ASTM, "ASTM D5: Standard Test Method for Penetration of Bituminous Materials," American Society for Testings and Materials, West Conshohocken, PA, United States (2006)

9. ASTM, "ASTM D36: Standard Test Method for Softening Point of Bitumen (Ring and Ball Apparatus)," American Society for Testing and Materials, West Conshohocken, PA, United States (2012)

10. ASTM, "ASTM D4402: Standard Test Method for Viscosity Determination of Asphalt at Elevated Temperatures Using a Rotational Viscometer," American Society for Testing and Materials, West Conshohocken, PA, United States (2013) 
11. ASTM, “ASTM D2872: Standard Test Method for Effect of Heat and Air on a Moving Film of Asphalt (Rolling Thin-Film Oven Test)," American Society for Testing and Materials, West Conshohocken, PA, United States (2012)

12. Asphalt Institute, Performance Graded Asphalt: Binder Specifications and Testing, Superpave Series No 1 (SP-1). Lexington, KY, USA.: The Asphalt Institute (2003) 